\title{
Changes in Intra-cerebral Environment in Patients Undergoing Tracheotomy: An Original Research
}

\author{
Kenichi Satoh ${ }^{1}$, Mami Chikuda', Ayako Ohashi', Miho Kumagai², Masahito Sato', \\ Shigeharu Joh ${ }^{1}$
}

\begin{abstract}
${ }^{1}$ Department of Reconstructive Oral and Maxillofacial Surgery, Division of Dental Anesthesiology, School of Dentistry, Iwate Medical University, Iwate 020-8505, Japan, ${ }^{2}$ Department of Developmental Oral Health Science, Division of Special Care Dentistry, School of Dentistry, Iwate Medical University, Iwate 020-8505, Japan
\end{abstract}

\begin{abstract}
Background and Objectives: Microvascular flap reconstruction has recently proven to be very reliable for repairing defects in the oral and maxillofacial cavity defects. Such patients often require a tracheotomy to stay in the intensive care unit post-operatively. Although tracheotomy is usually performed after oral intubation, details of the intra-cerebral oxygenation environment during tracheotomy are unclear. Using near-infrared spectroscopy, we investigated the changes in intra-cerebral oxygenation during exchange from oral to tracheal intubation in patients undergoing tracheotomy. Materials and Methods: We evaluated eight patients with an American Society of Anesthesiologists physical Status of I or II who were scheduled to undergo tracheotomy. Changes in the intra-cerebral levels of oxyhemoglobin (oxy-Hb), deoxyhemoglobin (deoxy-Hb), total hemoglobin (total-Hb), and cytochrome oxidase (cyt) were monitored during tracheotomy. Results: Blood pressure increased rapidly during exchange from an oral to tracheal intubation tube. The maximum oxy-Hb level $(3.5 \pm 2.4 \mathrm{nmol} / \mathrm{L})$ occurred $5 \mathrm{~min}$ after the exchange, the maximum deoxy-Hb level $(0.8 \pm 1.0 \mathrm{nmol} / \mathrm{L})$ occurred 5 min after the exchange, the maximum total-Hb level $(1.8 \pm 2.2 \mathrm{nmol} / \mathrm{L})$ occurred $5 \mathrm{~min}$ after the exchange, and the minimum cyt level $(-0.5 \pm 0.2 \mathrm{nmol} / \mathrm{L})$ occurred $7 \mathrm{~min}$ after the start of the operation. Conclusions: The intra-cerebral oxy-Hb and total-Hb levels increased after exchange from an oral to tracheal intubation tube during tracheotomy, and these hemodynamic changes attenuated the cerebral blood flow.
\end{abstract}

Key words: Intra-cerebral environment, oral and maxillofacial surgery, oxyhemoglobin, total hemoglobin, tracheotomy

\section{INTRODUCTION}

Oral and maxillofacial surgery with and without radiation therapy remains the current standard of

\begin{tabular}{|l|l|}
\hline \multicolumn{2}{|c|}{ Access this article online } \\
\hline \multicolumn{1}{|c|}{ Publisher } & $\begin{array}{l}\text { Website: } \\
\text { www.renupublishers.com }\end{array}$ \\
\cline { 2 - 3 } & $\begin{array}{l}\text { DOI: } \\
10.5958 / 2394-4196.2015 .00009 .6\end{array}$ \\
\hline
\end{tabular}

care for most patients with oral cancer. ${ }^{[1]}$ Surgeons are often faced with the challenge of achieving complete resection margins while preserving a functional swallowing mechanism to avoid postoperative dysphasia and aspiration. ${ }^{[2]}$ Microvascular flap reconstruction, which is performed by a plastic surgeon in our hospital, has recently proven to be very reliable for repairing defects in the oral cavity and oropharynx. ${ }^{[2]}$ Such patients are often on mechanical ventilation for a long period of time ${ }^{[3]}$ and stay in the intensive care unit post-operatively (for 5-7 days in our hospital) to prevent free flap failure, enhance primary

\footnotetext{
Address for correspondence:

Kenichi Satoh, Department of Reconstructive Oral and Maxillofacial Surgery, Division of Dental Anesthesiology, School of Dentistry, Iwate Medical University, 1-3-27 Chuo-dori, Morioka, Iwate 020-8505, Japan. Tel.: +81-19-6515111 (ext. 4331), Fax: +81-19-6520756, E-mail: satoken@iwate-med.ac.jp
}

Submission: 08 Apr 2015; Revision: 16 Apr 2015; Acceptance: 24 Apr 2015 
wound healing, ${ }^{[4,5]}$ and achieve restoration of bony and soft tissue after osteotomy. ${ }^{[6]}$

Tracheotomy is usually performed after oral intubation and before tumor resection in our dental hospital. Therefore, the oral intubation tube needs to be exchanged for a tracheal intubation tube (spiral tube). The details of the intra-cerebral oxygenation environment during this exchange, which often takes some time to accomplish, are not well known.

Near-infrared spectroscopy (NIRS) is a noninvasive bedside technique that may be used to monitor the intra-cerebral environment and is capable of measuring changes in the concentration of cerebral oxyhemoglobin (oxy-Hb), deoxyhemoglobin (deoxy$\mathrm{Hb}$ ), total hemoglobin (total-Hb), and cytochrome oxidase (cyt). ${ }^{[7]}$ Using NIRS, we investigated the changes in the intra-cerebral oxygenation environment during exchange from an oral to tracheal intubation tube in patients undergoing a tracheotomy.

\section{MATERIALS AND METHODS}

This observational study was approved by the Committee on Clinical Investigation for Human Research at Iwate Medical University.

We evaluated eight patients with an American Society of Anesthesiologists physical Status of I or II who were scheduled to undergo tracheotomy before tumor resection and micro-vascular flap reconstruction. The patients comprised six men and two women with a mean age of 53.8 years and mean weight of $55.8 \mathrm{~kg}$ [Table 1]. All patients underwent intravenous administration of atropine $(0.05 \mathrm{mg} / \mathrm{kg})$ and midazolam $(0.5 \mathrm{mg} / \mathrm{kg}) 30 \mathrm{~min}$ before admittance to the operating room. Anesthesia was induced with a mixture of either thiopental $(5.0 \mathrm{mg} / \mathrm{kg})$ or propofol $(2.0 \mathrm{mg} / \mathrm{kg})$ with fentanyl and vecuronium bromide $(0.1 \mathrm{mg} / \mathrm{kg})$, then maintained with sevoflurane (1.0-1.5\%) in oxygen (40.0\%). Fentanyl and remifentanil were administered after oral endotracheal intubation. The surgeon infiltrated the skin around the anterior region of the neck using $1 \%$ lidocaine in combination

Table 1: Demographic data

\begin{tabular}{lc}
\hline Patients $(n)$ & 8 \\
Age (years) & $53.8 \pm 5.8$ \\
Weight $(\mathrm{kg})$ & $55.8 \pm 3.8$ \\
Sex (male:female) & $6: 2$ \\
Type of surgery & Tracheostomy \\
\hline
\end{tabular}

Data are presented as mean \pm standard error with $5 \mathrm{ml}$ of 1/1,00,000 adrenaline. Local infiltration was carried out at two or three points at the anterior region of the neck. Tracheotomy was started, and the oral intubation tube was exchanged for a tracheal tube (spiral tube) almost 15 min after tracheostomy.

We continuously monitored the noninvasive blood pressure (BP), pulse rate (PR), and blood oxygen saturation $\left(\mathrm{SpO}_{2}\right)$ with a Life Scope $8^{\circledR}$ (Nihon Kohden, Tokyo, Japan) and the end-tidal carbon dioxide pressure, respiration rate, oxygen concentration, nitrous oxide concentration, and sevoflurane concentration with a capnometer (Capnomac Ultima; DatexEngstrom, Helsinki, Finland). BP and PR were measured every $2.5 \mathrm{~min}$. We also monitored changes in intra-cerebral oxy-Hb, deoxy-Hb, total-Hb, and cyt with a near-infrared oxygenation monitor (NIRO $500^{\circledR}$; Hamamatsu Photonics, Hamamatsu, Japan). The NIRO sensor was placed on the opposite sides of the forehead before starting the operation. The optodes of the NIRO were placed in an opaque optode holder supplied by the manufacturer, and the holder was secured to the forehead with tape. This resulted in an optode separation of $4.8 \mathrm{~cm}$. To ensure light shielding, the NIRO sensors were covered with crepe bandage

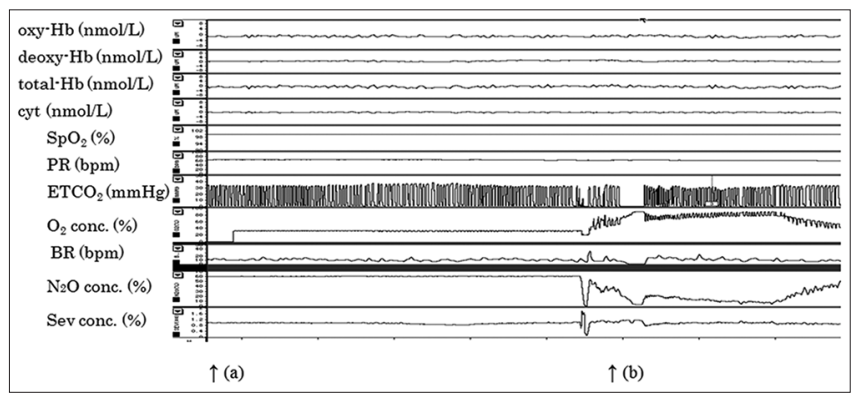

Figure 1: Changes in intra-cerebral oxygen environment and other parameters during tracheotomy. (a) operation start, (b) oral intubation tube is exchanged for a tracheal tube

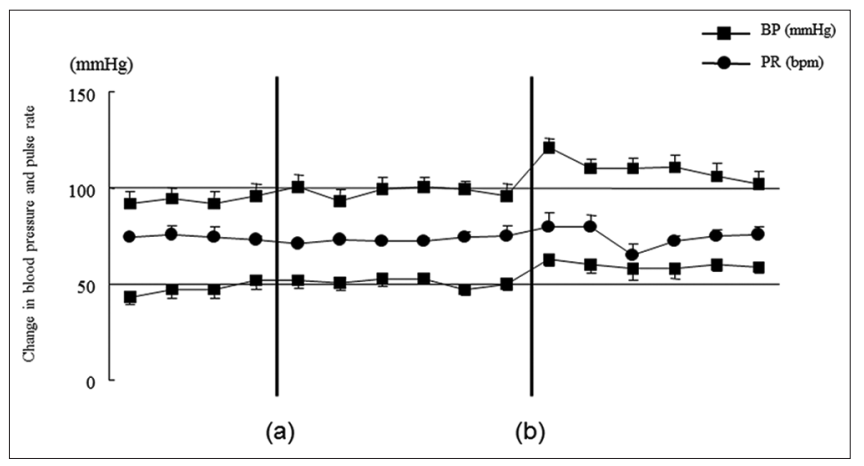

Figure 2: Changes in blood pressure and pulse rate during tracheotomy. (a) Operation start, (b) Oral intubation tube is exchanged for a tracheal tube. The blood pressure increases $2.5 \mathrm{~min}$ after the tube exchange 


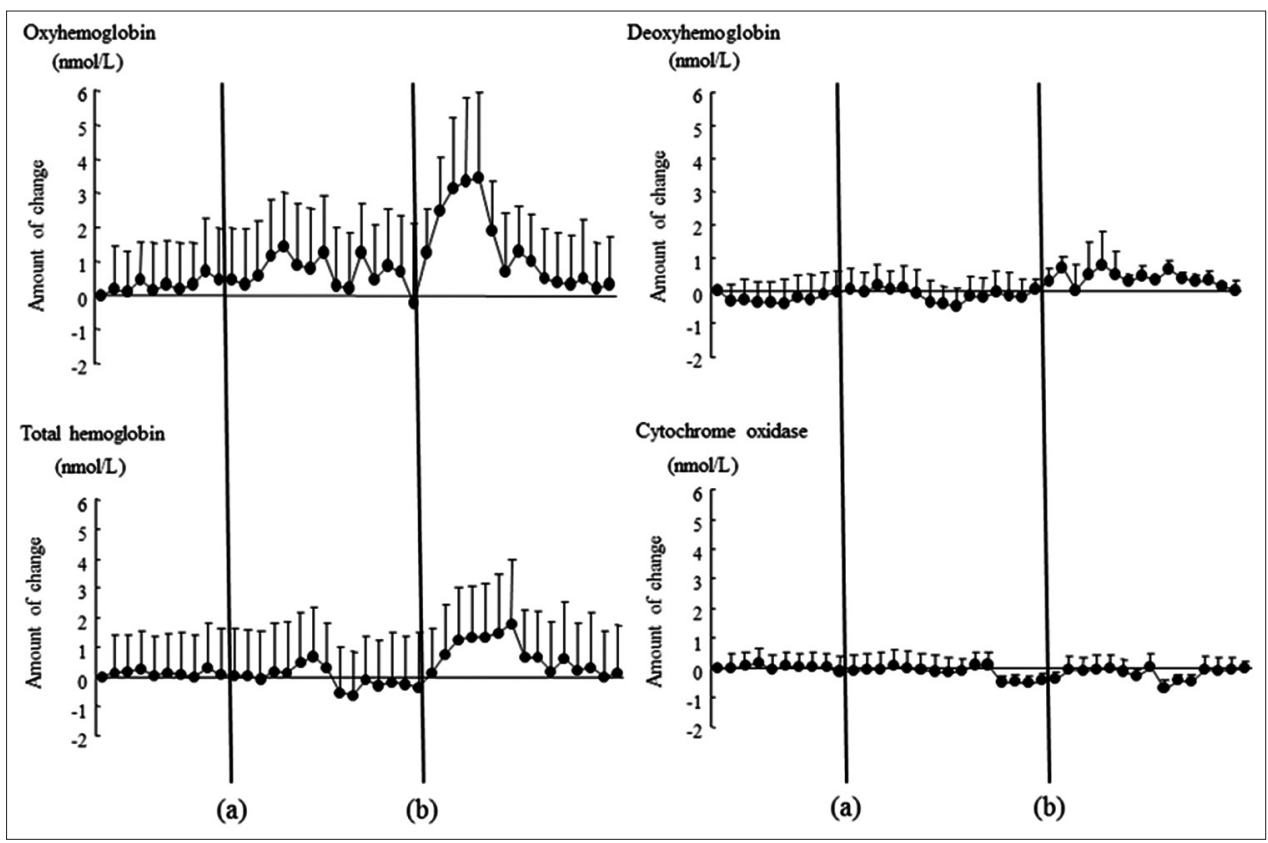

Figure 3: Changes in intra-cerebral oxygen environment during tracheotomy. (a) Operation start. (b) Oral intubation tube is exchanged for a tracheal tube. The maximum oxyhemoglobin level occurs $5 \mathrm{~min}$ after exchange of the oral intubation tube for a tracheal tube, the maximum deoxyhemoglobin level occurs $5 \mathrm{~min}$ after exchange of the tubes, the maximum total-hemoglobin level occurs 5 min after exchange of the tubes, and the minimum cyt level occurs 7 min after the start of the operation

wrapped loosely around the head. The NIRO measured the changes in parameters from a baseline that was set at zero at the start of measurement. Baseline measurements were made for 1 or 2 min. All parameters were continuously recorded using a PowerLab 4/25T data acquisition system (AD Instruments, Bella Vista, Australia). Each parameter 10 min before the start of the tracheostomy (control) was compared with the oxy-Hb, deoxy-Hb, total-Hb, and cyt levels every $1 \mathrm{~min}$.

Values are presented as mean \pm standard error. Intragroup comparisons were made using one-way Analysis of Variance for repeated measurements followed by Dunnett's test for multiple comparisons. Differences were considered statistically significant at $P<0.05$.

\section{RESULTS}

As shown in Figure 1, the changes in the intra-cerebral oxygen environment and other parameters were recorded using the PowerLab data system. The changes in invasive $\mathrm{BP}$ and $\mathrm{PR}$ were shown during osteotomy [Figure 2]. The $\mathrm{BP}, \mathrm{SpO}_{2}$, and $\mathrm{PR}$ were stable during tracheotomy, but the BP increased rapidly when the oral intubation tube was exchanged for a tracheal tube (spiral tube).

The maximum oxy-Hb level $(3.5 \pm 2.4 \mathrm{nmol} / \mathrm{L})$ occurred $5 \mathrm{~min}$ after the tube exchange $(n=8)$; the
oxy-Hb level rapidly increased after the exchange of the tubes and then rapidly decreased. The maximum deoxy-Hb level $(0.8 \pm 1.0 \mathrm{nmol} / \mathrm{L})$ occurred $5 \mathrm{~min}$ after the tube exchange $(n=8)$; the deoxy-Hb level transiently increased $5 \mathrm{~min}$ after exchange of the tubes and then decreased. The maximum total-Hb level (1.8 $\pm 2.2 \mathrm{nmol} / \mathrm{L}$ ) occurred $5 \mathrm{~min}$ after the tube exchange $(n=8)$, then decreased. The minimum cyt level $(-0.5$ $\pm 0.2 \mathrm{nmol} / \mathrm{L}$ ) occurred $7 \mathrm{~min}$ after the start of the operation $(n=8)$; the cyt level decreased 7 min after the start of the operation and then increased [Figure 3].

\section{DISCUSSION}

In the present study, we observed an increase in the intra-cerebral oxy-Hb and total-Hb levels after the oral intubation tube was exchanged for a tracheal tube during tracheotomy.

During tracheotomy, there was an increase in the oxy-Hb and total-Hb levels at 5 and $7 \mathrm{~min}$, respectively, and a slight increase in the deoxy-Hb level 5 min after the tube exchange; these increases were followed by decreases. The simultaneous increase in the oxy-HB and total$\mathrm{Hb}$ levels indicates an increase in the overall cerebral blood flow. The BP increased 2.5 min after changing to the tracheal tube, and the oxy-Hb and total-Hb simultaneously increased. In this study, changes in BP influenced the intra-cerebral environment. The increase 
in cerebral blood flow was caused by tracheal intubation or extubation, which is consistent with previous findings that cerebral hemodynamic changes may occur due to several anesthetic events. ${ }^{[8]}$ In one study, the oxy-Hb level significantly increased upon tracheal extubation because of an increase in cerebral blood flow. ${ }^{[8]}$ Cerebral blood flow increases in response to noxious tracheal stimuli in patients with tracheal intubation because of a stimulated increase in muscle afferent activity. ${ }^{[9]}$ When the oral intubation tube is exchanged for a tracheal tube, the BP increases, which increases the cerebral blood flow. Hemodynamic changes that occur secondary to tube exchange attenuate the cerebral blood flow. ${ }^{[10]}$ Therefore, it is prudent to prevent $\mathrm{BP}$ changes resulting in excessively high or low BP when an oral intubation tube is exchanged for a tracheal tube during tracheotomy.

In conclusion, we observed an increase in the intracerebral oxy-Hb and total-Hb levels after the exchange of an oral intubation tube for a tracheal tube during tracheotomy. These hemodynamic changes appear to attenuate the cerebral blood flow. It is prudent to prevent $\mathrm{BP}$ changes resulting in excessively high or low $\mathrm{BP}$ during tracheotomy.

\section{REFERENCES}

1. Muir C, Weiland L. Upper aerodigestive tract cancers. Cancer 1995; 75:147-53.
2. Jesse MT, Ryan ME, Eshelman A, Ghanem T, Williams AM, MillerMatero LR, et al. Integrated psychological care in head and neck cancer: Views from health care providers, patients, and supports. Laryngoscope 2014.

3. Duran M, Abdullayev R, Cömlekçi M, Süren M, Bülbül M, Aldemir T. Comparison of early and late percutaneous tracheotomies in adult intensive care unit. Rev Bras Anestesiol 2014;64:438-42.

4. Suh JD, Sercarz JA, Abemayor E, Calcaterra TC, Rawnsley JD, Alam D, et al. Analysis of outcome and complications in 400 cases of microvascular head and neck reconstruction. Arch Otolaryngol Head Neck Surg 2004;130:962-6.

5. Abemayor E, Blackwell KE. Reconstruction of soft tissue defects in the oral cavity and oropharynx. Arch Otolaryngol Head Neck Surg 2000;126:909-12.

6. Roumanas ED, Garrett N, Blackwell KE, Freymiller E, Abemayor E, Wong WK, et al. Masticatory and swallowing threshold performances with conventional and implant-supported prostheses after mandibular fibula free-flap reconstruction. J Prosthet Dent 2006;96:289-97.

7. Owen-Reece H, Elwell CE, Harkness W, Goldstone J, Delpy DT, Wyatt JS, et al. Use of near infrared spectroscopy to estimate cerebral blood flow in conscious and anaesthetized adult subjects. Br J Anaesth 1996;76:43-8.

8. Morimoto Y, Kmmotsu O, Hisano K, Hua Y, Tang S, Morimoto Y, et al. Changes in cerebral oxygenation state and blood volume during tracheal intubation. Circ Contemp 2003;24:124-30.

9. Lanier WL, Iaizzo PA, Milde JH, Sharbrough FW. The cerebral and systemic effects of movement in response to a noxious stimulus in lightly anesthetized dogs. Possible modulation of cerebral function by muscle afferents. Anesthesiology 1994;80:392-401.

How to cite this article: Satoh K, Chikuda M, Ohashi A, Kumagai M, Sato M, Joh S. Changes in Intra-cerebral Environment in Patients Undergoing Tracheotomy: An Original Research. Int J Dent Med Spec 2015;2(2):5-8.

Source of Support: None; Conflict of Interest: None 